\title{
Arterial hypertension associated with somatic pathology in present-day practice of internal diseases
}

\author{
Yurii A. Nikolaev, Igor M. Mitrofanov, Vladimir Ya. Polyakov, Nina. A. Dolgova \\ Scientific Center of Clinical and Experimental Medicine, Siberian Branch of The Russian Academia of Medical Science, Novosibirsk, \\ Russia; *Corresponding Author: vpolyakov15@mail.ru
}

Received 4 December 2013; revised 29 December 2013; accepted 9 January 2014

Copyright (C 2014 Yurii A. Nikolaev et al. This is an open access article distributed under the Creative Commons Attribution License, which permits unrestricted use, distribution, and reproduction in any medium, provided the original work is properly cited. In accordance of the Creative Commons Attribution License all Copyrights (C) 2014 are reserved for SCIRP and the owner of the intellectual property Yurii A. Nikolaev et al. All Copyright (C) 2014 are guarded by law and by SCIRP as a guardian.

\section{ABSTRACT}

Dynamics of regional and gender features of occurrence of arterial hypertension associated with diseases of gallbladder, biliary ducts and pancreas for 2003-2011 was analyzed. There researched 23,310 patients (9111 males and 14,188 females) treated in clinic of scientific centre of clinical and experimental medicine SB RAMS. Occurrence of such combination, depending on gender, residence (the Novosibirsk region (NR) or Yakutia) as well as in age subgroups (16 - 39, 40 - 59 and over 60) was estimated. Occurrence of arterial hypertension associated with diseases of gallbladder, biliary ducts and pancreas was observed more in male of Subgroup I, living in NR and Yakutia. In 2003-2008 in female of Subgroup III, living in NR comorbidity pathology was observed more frequently than in male. In Subgroup III in female of NR occurrence of combined pathology was maximum (36.6\%) 20062008, in female of Yakutia-38.5\% in 2003-2005. Dependence of occurrence of combined pathology on residence was observed in male. In 20032011 in male of Yakutia combined pathology was observed frequently than in male of NR. Occurrence of comorbidity pathology, depending on gender and age was typical for inhabitants of NR. In Group I comorbidity pathology was frequently observed in male, in Group III-in female. It is necessary to develop regional strategies for observing patients with combined pathologies to improve prevention, rehabilitation and treatment of patients with arterial hypertension associated with diseases of gallbladder, biliary ducts and pancreas.

\section{KEYWORDS}

Arterial Hypertension; Somatic Pathology; Comorbidity; Siberia; North Region

\section{INTRODUCTION}

Increase of occurrence of comorbidity pathology in therapeutic patients is an important problem in general practice. Possibly it is connected with population aging, increase of quality and availability of the new diagnostic methods, change of man's lifestyle, diversity of extremely damaging factors. Risk factors are the same for different nosologic forms. Today the methods of treatment of main diseases do not include the optimal therapeutic approaches. Development of new approaches for diagnostics and treatment of comorbidity diseases in general practice of inner diseases is of great significance [1-4]. Comorbidity is not only a combination of diseases but their pathological interrelation [5,6]. Evolution of pathological processes in man should not be excluded to be a reason of new cross-pathogenetic mechanisms of diseases.

Prevention of chronic non-infectious diseases is the prior trend in medicine for increase of lifespan and life quality of people [7-10].

Arterial hypertension, pathology of gallbladder, biliary ducts and pancreas are widely spread chronic non-infectious diseases. Study of the occurrence of arterial hypertension associated with pathology of gallbladder, biliary ducts and pancreas depending on gender, age and residence is considered to be actual. $70 \%-90 \%$ diseases are combined, so it is difficult to analyze risk factors, disease prognosis, determine differentiated methods for their treat- 
ment and prevention. The problem is typical for the northern regions, where man's organism is influenced by diversity of extreme natural factors, resulting in pathogenetically interbonded complication of combined pathology $[11,12]$. Thus it is necessary to know about population health state in these regions, features of formation and manifestation of combined chronic non-infectious pathology.

The aim of the work was to study features of occurrence of arterial hypertension associated with diseases of gallbladder, biliary ducts and pancreas depending on residence, gender and age in 2003-2011.

\section{MATERIAL AND METHODS}

The research was performed according to the principles of the Helsinki Declaration (2000) with 23,310 patients being examined and treated in clinic of Research centre of clinical and experimental medicine SB RAMS (Novosibirsk). Group I consisted of 19,677 residents of the Novosibirsk region (NR), 7268 male and 12,406 female. Group II-3633 residents of republic SAKHA (Yakutia), 1843 male and 1790 female. The age of the examined was in the range of $16-92$ years. Average male age- $51.2 \pm 0.2$, average female age $-53.8 \pm 0.1$. No significant differences in average age was noted.

Occurrence of arterial hypertension, associated with diseases of gallbladder, biliary ducts and pancreas was analyzed. Clinical, functional and laboratory diagnostic methods were used. All detected diagnoses as nosologic forms and ICD were taking into consideration. Disease code was defined according to ICD-10.

Arterial hypertension, associated with diseases of gallbladder, biliary ducts and pancreas was considered to be both as a basic and concomitant disease.

Arterial hypertension was related to I10-I15 classes of ICD-10, diseases of gallbladder, biliary ducts and pancreas in K80-K87 classes.
To analyzes the dynamics of occurrence of arterial hypertension, associated with gallbladder, biliary ducts and pancreas pathology, all patients were divided in three subgroups, depending on being in the clinic-20032005-7141 persons, 2006-2008-7990 persons, 20092011—8179 persons.

The data were analyzed in all age groups and in age subgroups: Subgroup I-16 - 39 years, Subgroup II—40 - 59 years, Subgroup III—over 60 years.

Statistical data processing was performed using STATISTICA v.7.0 (Stat Soft Incorporared, US).

Frequency features were expressed in percents (\%) and standard error of a share (\%+Sp), 3-criteria was used to prove statistical significant differences.

In case of multiple comparisons Bonferroni's amendment was applied. The significance level was $5 \%$ or $\alpha=$ 0.05 .

\section{RESULTS AND DISCUSSION}

In 2003-2005 combined pathology was observed by $7.8 \%$ higher in patients, inhabitants of the North, independently on age a (Table 1 ).

There observed combined pathology by $23.8 \%$ higher in female compared to male in NR. In Group I combined pathology was frequently observed in patients, living in Yakutia compared to patients, living in NR both in male (14.6\% and 6.4\%, correspondingly; $p=0.005)$ and in female (5.6\% and $1.0 \%$, correspondingly; $\mathrm{p}=0.0001)$ as presented in Table 2. In this group combined pathology was more frequently observed in male than in female, living both in NR $(\mathrm{p}<0.0001)$ and in Yakutia $(\mathrm{p}=$ 0.0036) (Figure 1).

In Subgroup II combined pathology was frequently observed in female, living in the North $(26.4 \%)$ compared to female, living in the NR $(19.7 \%)(p=0.0007)$ as presented in Table 2.

In Subgroup III male-northerners had combined pa-

Table 1. Frequency of occurrence of arterial hypertension (I10-I15, ICD-10) associated with diseases of gallbladder, biliary ducts and pancreas (K80-K87, ICD-10) in male.

\begin{tabular}{ccccc}
\hline Hospitalization (years) & Age & Novosibirsk region (Russia) & Republic of Saha (Yakutia) & $\mathrm{p}$ \\
\hline \multirow{2}{*}{$2003-2005$} & 16 - 39 years & $6.4 \pm 1.1$ & $14.6 \pm 2.4$ & $\mathbf{0 . 0 0 0 5}$ \\
& 40 - 59 years & $20.5 \pm 1.4$ & $23.7 \pm 1.7$ & 0.1331 \\
& 60 years and older & $19.7 \pm 1.6$ & $28.6 \pm 3.6$ & $\mathbf{0 . 0 1 5 8}$ \\
& Total & $16.8 \pm 0.8$ & $22.5 \pm 1.3$ & $\mathbf{0 . 0 0 0 1}$ \\
$2006-2008$ & 16 - 39 years & $7.7 \pm 1.1$ & $14.9 \pm 3.2$ & $\mathbf{0 . 0 1 2 0}$ \\
& 40 - 59 years & $19.5 \pm 1.2$ & $28.4 \pm 2.2$ & $\mathbf{0 . 0 0 0 2}$ \\
& 60 years and older & $30.6 \pm 1.6$ & $35.0 \pm 5.3$ & 0.4156 \\
$2009-2011$ & Total & $20.7 \pm 0.8$ & $26.6 \pm 1.8$ & $\mathbf{0 . 0 0 1 5}$ \\
& 16 - 39 years & $6.7 \pm 1.1$ & $16.7 \pm 6.2$ & $\mathbf{0 . 0 2 5 9}$ \\
& 40 - 59 years & $20.4 \pm 1.2$ & $28.9 \pm 4.0$ & $\mathbf{0 . 0 2 5 8}$ \\
& 60 years and older & $27.8 \pm 1.4$ & $35.0 \pm 7.5$ & 0.3207 \\
\hline
\end{tabular}


Table 2. Frequency of occurrence of arterial hypertension (I10-I15, ICD-10) associated with diseases of gallbladder, biliary ducts and pancreas (K80-K87, ICD-10) in female.

\begin{tabular}{|c|c|c|c|c|}
\hline Hospitalization (years) & Age & Novosibirsk region (Russia) & Republic of Saha (Yakutia) & $\mathrm{p}$ \\
\hline \multirow{4}{*}{$2003-2005$} & $16-39$ years & $1.0 \pm 0.4$ & $5.6 \pm 1.7$ & 0.0001 \\
\hline & 40 - 59 years & $19.7 \pm 1.1$ & $26.4 \pm 1.7$ & 0.0007 \\
\hline & 60 years and older & $31.6 \pm 1.3$ & $38.5 \pm 4.1$ & 0.0950 \\
\hline & Total & $20.8 \pm 0.7$ & $24.4 \pm 1.4$ & 0.0164 \\
\hline \multirow{4}{*}{ 2006-2008 } & $16-39$ years & $3.1 \pm 0.6$ & $4.1 \pm 2.0$ & 0.5996 \\
\hline & $40-59$ years & $21.7 \pm 1.0$ & $23.0 \pm 2.2$ & 0.5795 \\
\hline & 60 years and older & $36.6 \pm 1.2$ & $26.6 \pm 5.0$ & 0.0708 \\
\hline & Total & $24.3 \pm 0.7$ & $20.2 \pm 1.7$ & 0.0337 \\
\hline \multirow{4}{*}{ 2009-2011 } & $16-39$ years & $1.2 \pm 0.4$ & $2.8 \pm 2.7$ & 0.4051 \\
\hline & $40-59$ years & $16.3 \pm 0.8$ & $22.3 \pm 3.3$ & 0.0514 \\
\hline & 60 years and older & $30.8 \pm 1.0$ & $20.0 \pm 5.7$ & 0.1015 \\
\hline & Total & $20.3 \pm 0.6$ & $18.9 \pm 2.5$ & 0.5958 \\
\hline
\end{tabular}

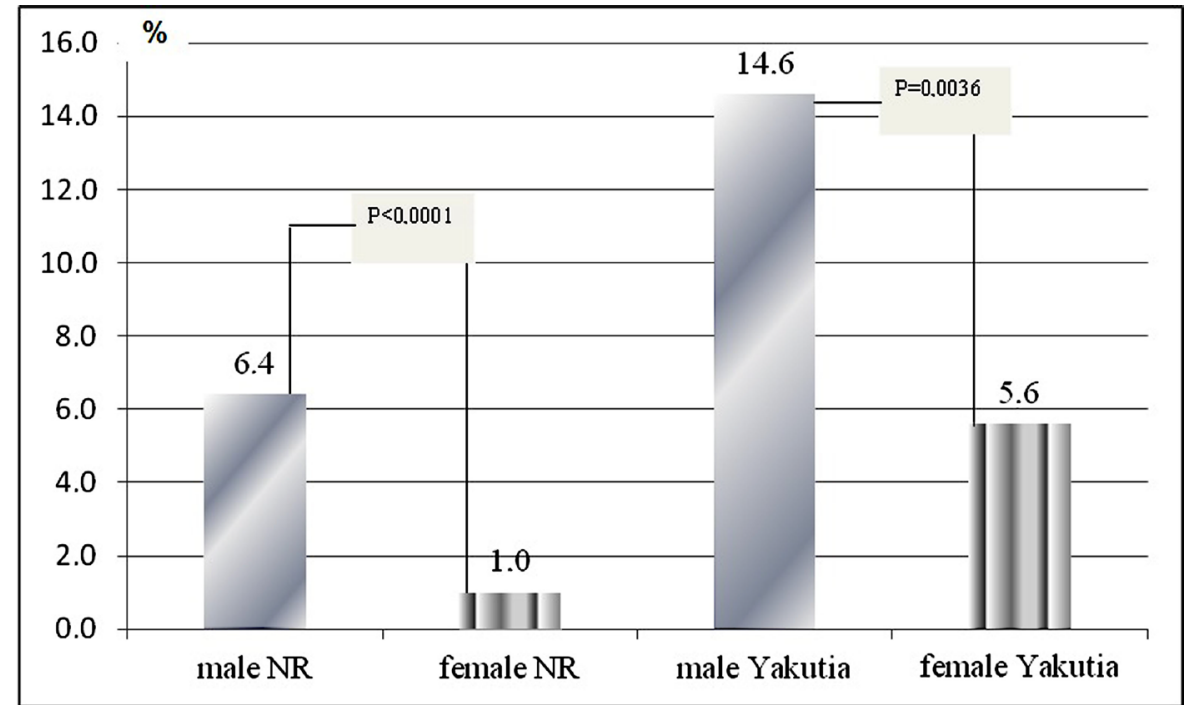

Figure 1. Gender differences of occurrence of arterial hypertension associated with diseases of gallbladder, biliary ducts and pancreas in patients of 16 - 39 aged in 2003-2005.

thology by $45.1 \%$ frequently compared to male, living in NR ( $p=0.0158)$. Occurrence of combined pathology was frequently observed in female than in male, living in NR.

In 2006-2008 in male of Group I, living in Yakutia, combined pathology was by $93.5 \%$ higher compared to male of NR ( $p=0.0120$ ) (Table 1$)$. However, comorbidity pathology was higher in male of NR and Yakutia, compared to female of these regions (Figure 2).

In Subgroup II combined pathology was by $45.6 \%$ higher in male, living in the North than in male, living in NR.

In Subgroup III occurrence of combined pathology was by $19.6 \%$ higher in female than in male of NR.

Thus, we observed combined pathology more frequently in male of Yakutia (26.6\%) than in male of the NR (20.7\%, p = 0.0015).
In NR female had comorbidity pathology by $17.3 \%$ higher compared to male. In Yakutia comorbidity pathology was observed more frequently in male than in female.

In 2009-2011 in Subgroup I occurrence of comorbidity pathology was higher in compared to male of NR ( $\mathrm{p}=$ 0.0259).

Occurrence of combined pathology was in 5.6 higher in male than in female, living in NR $(\mathrm{p}<0.0001)$.

In Subgroup II combined pathology in male, living in Yakutia was observed in 1.4 frequently than in male of NR. Gender differences were typical only for the NR: combined pathology was by $25.1 \%$ higher in male than in female.

Thus comorbidity pathology was by $37.4 \%$ higher in male of Yakutia compared to male of the NR ( $p=0.01)$. It was typical for female of Yakutia. 


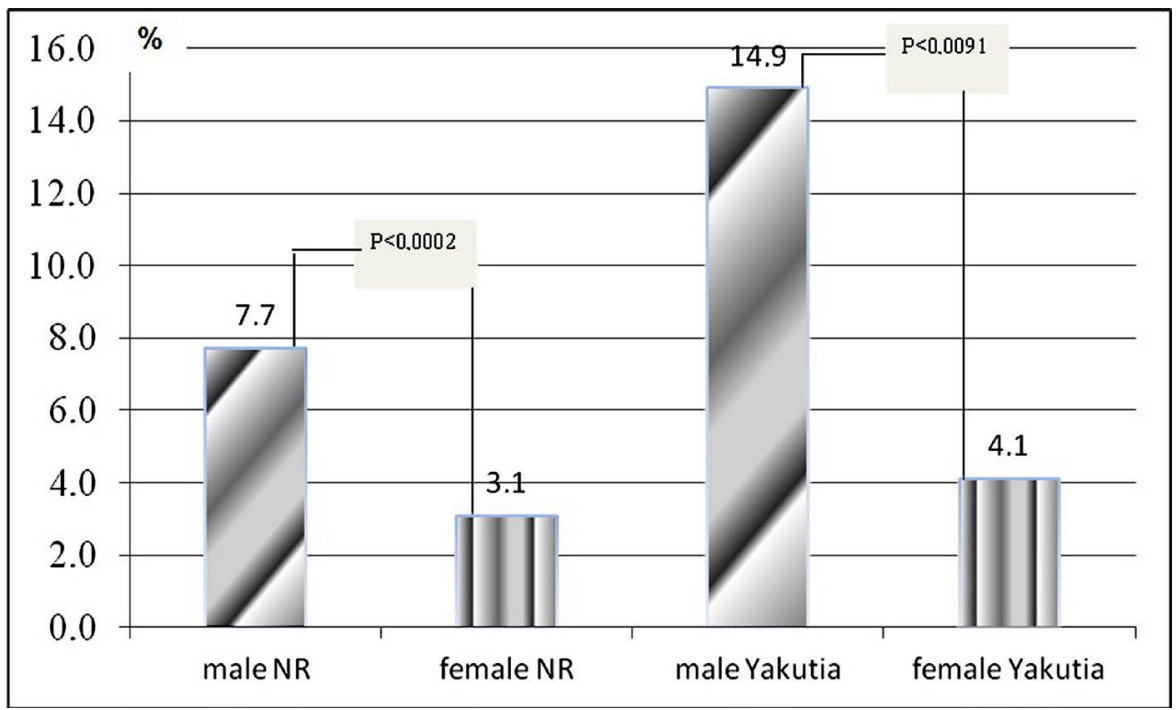

Figure 2. Gender differences of occurrence of arterial hypertension associated with diseases of gallbladder, biliary ducts and pancreas in patients of 16 - 39 aged in 2006-2008.

In 2003-2011 in Groups I-II no dynamics of occurrence of comorbidity pathology was revealed in male, living in NR.

In male over 60 combined pathology was $19.7 \%$ in 2003-2005, increased to $30.6 \%$ in 2006-2008 and was the same in 2009-2011.

In female of II group there observed high combined pathology in 2006-2008 and low in 2003-2005 and 20092011.

In Group III in female of NR combined pathology was maximum (36.6\%) in 2006-2008, in female of Yakutia$38.5 \%$ in $2003-2005$.

The feature revealed showed that combined pathology was more frequently occurred in female, however, gender differences depended on residence and age.

The most low occurrence of combined pathology was in female of Group I, living in the NR region, within 2003-2005 (1.0\%), in male of this group-6.4\%.

But in 2006-2011 in female of Group III, living in NR, occurrence of combined pathology was $36.6 \%$.

Number of combined diseases is known to depend on age. Comorbidity increased from $10 \%$ in persons of 19 aged to $80 \%$ in persons over 80 aged [13]. In this case the number of chronic diseases changed from $2.8 \%$ in young persons to $6.4 \%$ and more in adults [14].

Presently a role of comorbidity in general practice of inner diseases isn't paid attention enough while course of disease depends on combination of pathological processes. Thus, modern targeted medicine need to consider the epidemiological and pathogenetic features of comorbidity.

The multifactor approach to treatment and prevention of chronic non-infectious diseases, including comorbidity pathology at arterial hypertension is considered to be effective.

It is known that prognoses for developing of disease and life quality of patients with comorbidity pathology is worsening more earlier than in patients with mononosologies [1]. Some complications appeared at treatment [15]. In this case development of optimal regional strategy for observation patients with combined nosologies and improvement of prevention, rehabilitation and treatment the patients is needed.

\section{CONCLUSIONS}

High occurrence of arterial hypertension associated with diseases of gallbladder, biliary ducts and pancreas was observed in male of Group I, living in the NR and Republic Sakha (Yakutia).

In 2003-2008 in female of Group III, living in NR comorbidity pathology occurred more frequently compared to male.

In female of NR combined pathology was maximum (36.6\%) 2006-2008, in female of Yakutia-38.5\% in 2003-2005.

Dependence of combined pathology on residence was typical for male than for female. In 2003-2011 combined pathology was frequently observed in male of Yakutia than in male of NR.

Occurrence of comorbidity pathology, depending on gender and age was typical for inhabitants of NR. In Group I comorbidity pathology was frequently observed in male, in Group III-in female.

It is necessary to develop regional strategies for observing patients with combined pathologies to improve prevention, rehabilitation and treatment of patients with arterial hypertension associated with diseases of gallbladder, biliary ducts and pancreas. 


\section{REFERENCES}

[1] Fortin, M., Lapointe, L., Hudon, C., Vanasse, A., Ntetu, A.L. and Maltais, D. (2004) Multimorbidity and quality of life in primary care: A systematic review. Health and Quality of Life Outcomes, 20, 2-51.

[2] Lazebnik, L.B. (2005) Multimorbidity and aging. Consilium-Medicum, 12.

[3] Oganov, R.G. (2004) Effective strategy of prolonged management of non-infectious diseases in Russia. Disease Prevention and Health Strengthening, 1, 3-6.

[4] Belyalov, F.I. (2012) Treatment of inner diseases associated with comorbidity. Manuscript, Irkutsk.

[5] Belyalov, F.I. (2011) Comorbidity. http://therapy.irkutsk.ru/edcomorbid.htm

[6] Schellevis, F.G., van der Velden, J. and van de Lisdonk, E. (1993) Comorbidity of chronic diseases in general practice. Journal of Clinical Epidemiology, 46, 469-473. http://dx.doi.org/10.1016/0895-4356(93)90024-U

[7] Starfield, B., Lemke, K.W. and Bernhardt, T. (2003) Comorbidity: Implications for the importance of primary care in case management. Annals of Family Medicine, 1, 8-14. http://dx.doi.org/10.1370/afm.1

[8] van Weel, C. and Schellevis, F.G. (2006) Comorbidity and guidelines: Conflicting interests. Lancet, 367, 550551. http://dx.doi.org/10.1016/S0140-6736(06)68198-1

[9] (1998) DCCT Research Group Reliability and validity of a diabetes quality of life measure for the diabetes control and complications trial (DCCT). Diabetes Care, 11, 725-
732.

[10] Michelson, H., Bolund, C. and Brandberg, Y. (2000) Multiple chronic health problems are negatively associated with health related quality of life (HRQOL) irrespective of age. Quality of Life Research, 9, 1093-1104. http://dx.doi.org/10.1023/A:1016654621784

[11] Daryanina, S.A., Paltsev, A.I. and Nikolaev, Yu.A. (2009) Features of variability of heart rhythm at arterial hypertension associated with diseases of biliary in newcomers of the north. Theraupetic Archive, 4, 76-78.

[12] Epdakova, T.K., Salamatina, L.V. and Buganov, A.A. (2007) Endothelial function in patients with arterial hypertension in the far north. Disease Prevention and Health Promotion, 2, 34-38.

[13] van den Akker, M., Buntinx, F., Metsemakers, J.F., Roos, S. and Knottnerus, J.A. (1998) Multimorbidity in general practice: Prevalence, incidence, and determinants of cooccurring chronic and recurrent diseases. Journal of Clinical Epidemiology, 51, 367-375.

http://dx.doi.org/10.1016/S0895-4356(97)00306-5

[14] Fortin, M., Bravo, G., Hudon, C., Vanasse, A. and Lapointe, L. (2005) Prevalence of multimorbidity among adults seen in family practice. Annals of Family Medicine, 3, 223-228. http://dx.doi.org/10.1370/afm.272

[15] Wang, P.S., Avorn, J., Brookhart, M.A., Mogun, H., Schneeweiss, S., Fischer, M.A. and Glynn R.J. (2005) Effects of noncardiovascular comorbidities on antihypertensive use in elderly hypertensives. Hypertension, 46, 273-279. http://dx.doi.org/10.1161/01.HYP.0000172753.96583.e1 